IGUSABDER, 6 (2018): 551-560

\title{
Serebral Palsi’de Kranial Antropometrik Değerlendirme: Bir Pilot Çalışma
}

\author{
İlknur ATKIN ${ }^{*}$, Gülşah KINALI**
}

\section{Öz}

Amaç: Kranial asimetri günümüzde pediatrik fizyoterapi alanında önemli bir değerlendirme parametresi olmaya başlamıştır. Fizyoterapistler, vücut fonksiyonları ile bağlantılı olan kranial bölge hakkında daha fazla çalışma yapmaktadırlar. Ancak halen kanıta dayalı çalışmalara ihtiyaç vardır. Kranial asimetri ayrıca, bir tamamlayıcı terapi metodu olan osteopati'nin de önemli bir değerlendirme yöntemidir.

Yöntem: Bu çalışma bir fizik tedavi ve rehabilitasyon hastanesine gelen 1-12 yaş arasındaki 24 Serebral Palsi ve aynı yaş grubundaki 22 sağlıklı çocuk üzerinde yapıldı. Kranial antropometrik değerler standart pozisyonlarda kranial kaliper kullanılarak ölçüldü.

Bulgular: Serebral Palsili bireylerin kafa çapı ortalama (48 mm), uzunluğu $(136 \mathrm{~mm})$ ve genişliği (123 mm) ve sağlıklı bireylerin kafa çapı (53 mm), uzunluğu (152 mm) ve genişliği (133 m) idi. Serebral palsili bireylerin değerleri, sağlıklı bireylerden anlamlı derecede düşüktü $(\mathrm{p}=0.00, \mathrm{p}=0.00, \mathrm{p}=0.00)$.

Sonuç: Araştırma sonuçlarına göre, kranial asimetri ile ilgili antropometrik ölçümlerinin Serebral Palsili çocukların fiziksel değerlendirmeleri içinde rutin bir protokol olarak uygulanması ve kranial anomalilerin fizyoterapistler tarafından göz önüne alınması gerektiği kanısına varılmıştır. Kranial asimetrilerin sıklığı ve karşı önlem olarak kranial mobilizasyonların etkinliği konusunda daha fazla çalışmaya ihtiyaç vardır.

Anahtar Sözcükler: Serebral palsi, kranial antropometri, büyüme, çocuklar, osteopati.

\section{Özgün Araştırma Makalesi (Original Research Article)}

Geliş / Received: 16.10 .2018 \& Kabul / Accepted: 12.11.2018

${ }^{*}$ Fizyoterapist (MSc), Bahçeşehir Üniversitesi, Sağllk Bilimleri Enstitüsü, Fizyoterapi ve

Rehabilitasyon Bölümü, İstanbul, Türkiye, E-posta: iknr-3478@hotmail.com, ORCID ID https://orcid.org/0000-0002-6021-1112

** Dr. Öğr. Üyesi, İstanbul Gelişim Üniversitesi, Sağllk Bilimleri Yüksekokulu, Fizyoterapi ve Rehabilitasyon Bölümü, İstanbul, Türkiye, E-posta: gulsah.kinali@gmail.com, 


\title{
Assessment of Cranial Antrophometry in Cerebral Palsy: A Pilot Study
}

\begin{abstract}
Aim: Cranial asymmetry is now an important evaluation parameter in the field of pediatric physiotherapy. Physiotherapists are studying more about the cranial region associated with body functions. However, there is still a need for evidence-based work. Cranial asymmetry is also an important evaluation method of osteopathy, a complementary therapy method. Method: This study was conducted in 24 children with Cerebral Palsy between the ages of 1-12 and 22 healthy children in the same age group at a physical therapy and rehabilitation hospital. This study was performed on 24 cerebral palsies between 1-12 years old who came to a physical therapy and rehabilitation hospital and 22 healthy children in the same age group. Cranial anthropometric values were measured using cranial calliper in standard positions.

Findings: Cerebral palsy subjects had mean head diameter $(48 \mathrm{~mm})$, length $(136 \mathrm{~mm})$ and width $(123 \mathrm{~mm})$, and healthy subjects had head diameter $(53 \mathrm{~mm})$, length $(152 \mathrm{~mm})$ and width $(133 \mathrm{~m})$. Values of individuals with cerebral palsy were significantly lower than healthy subjects ( $\mathrm{p}=0.00, \mathrm{p}=0.00, \mathrm{p}=0.00)$.
\end{abstract}

Conclusion: We concluded that the anthropometric measurements of cranial asymmetry should be applied as a routine protocol in the physical assessment of children with cerebral palsy and that cranial anomalies should be considered by physiotherapists, according to the results of our study. There is a need to study more about the frequency of cranial asymmetry and the effectiveness of cranial mobilizations as countermeasures.

Keywords: Cerebral palsy, cranial antrophometry, growth, children, osteopathy.

\section{Giriş}

Serebral Palsi, özürlülüğe neden olan ve çocuk ile ailesinin hayatını etkileyen bir sendromdur. Genellikle ilerlemeyen bir durumdur fakat zaman için de kötüleştiği de görülebilir. Serebral palsi 1000 doğumda $1,7-3$ arasında görülme sılklı̆ değişmektedir¹. Prenatal hipoksi, metabolik sorunlar, genetik düzensizlik, enfeksiyon nedenli, travmatik ve diğer nedenlerle olabilir. Fonksiyonel motor özürlülüğe çeşitli türden bilişsel problemler eşlik edebilir. Fizyoterapi sonrasında Gross Motor Fonksiyon skorlamasına bakıldığında, motor fonksiyonun geliştiği görülmüştür² ${ }^{2}$ Çoğunlukla Serebral Palsili çocuklarda ve ergenlerde zihinsel sağlık koşulları ve sorunları bildirilmektedir3. Serebral Palsili bireylerin yaklaşık yarısında zihinsel problemler 
mevcuttur ve bireylerde genellikle epilepsi, reflü, duyusal bozukluklar gibi ilave semptomlar da vardır3,4. $\mathrm{Bu}$ sorunlardaki yaygınlıkların prevelans aralıklarını belirlemek için çalışmalar yapılmaktadır.

Serebral palsinin tam bir tedavisi yoktur ancak ikincil komplikasyonları engellemek ve fonksiyonelliği arttırmak için yöntemler mevcuttur. Bu sendromun klinik özellikleri zamanla değişmekle beraber, spesifik olarak Serebral Palsi sendromu ancak 3-5 yaşından sonra fark edilir5. Serebral Palsi, doğum öncesi, doğum sırası ve doğum sonrası beyindeki bir hasar sonucu meydana gelir. Ortaya çıkan bu durum spastisite, kas zayıflığı, tremor, koordinasyon bozukluğu gibi sekellere neden olur. Ayrıca mental retardasyon, konuşmada ve görmede gerilik gibi bozukluklarda meydana gelir. Skolyoz ve ayak ekin deformitesi Serebral Palside nöromüsküler dengesizliğe bağlı olarak sık gelişen ikincil fiziksel deformitelerdir. Serebral Palsi ile skolyoz arasında kuvvetli bir bağ vardır. Thomas ve arkadaşları Serebral Palside skolyoz görülme olasılığını \%21 bulmuştur' ${ }^{6}$ Bunlarla birlikte kranial deformiteler de oluşabilmektedir. Az gelişen beyin yapısına bağlı mikrosefali, uzun süreli hareketsizlik ve yatmaya bağlı olarak baş düzleşmeleri ya da bir tarafa asimetri gelişebilmektedir. Bebeklerdeki bu yatış pozisyonlarının tercihi kranial asimetri oluşumuna neden olmaktadır. Yapılan çalışmalarda yatış pozisyonunun sonucu olarak, kafatası araştırması yapıldığında primer sonuç olarak plagiosefali bulunmuştur7 ${ }^{7}$ Bu asimetri daha çok sağa ya da sola rotasyon sağlayan bebeklerde görülmüştür.

Kranium, merkezi sinir sistemini çevrelemesi bakımından en önemli kemiksel anatomik yapılardan biridir. Merkezi sinir sisteminin gelişimine bağlı olarak gelişir ve şekillenir. Serebral Palsili çocuklarda çeşitli nedenlere bağlı gelişen beyin hasarı ve gelişim bozukluğu kraniumun büyümesini de etkilemektedir. Büyüme ve gelişme birbirinden ayrılamaz iki süreçtir. Bu nörolojik hastalık gelişme ve büyümeyi etkiler. Melunovic ve $\operatorname{ark}^{8}$ yaptığ bağlı olarak antropometrik değerlerin değişimini incelemiştir. Serebral Palsili bireylerde hem beslenme hem de hareket bozukluğuna bağlı olarak antropometrik değerler etkilenmektedir. Bu durum kranial değerleri de etkilemektedir.

Kranium biyomekanisi ve büyümesi ile ilgili çalışan bilim adamları arasında Andrew Taylor Still ve William Garner Sutherland bulunmaktadır. Kranium büyümesinin nörogelişimsel hastalıklar ile bağlantısını araştıran Andrew Taylor Still, ellerle 
uygulanan ve ritmik uyarılarla kranium büyümesini destekleyen, asimetrileri düzelten bir yöntem olan Kranio Sakral osteopati yöntemini geliştirmiştir. Kranio Sakral Terapi, osteopati yönteminin bir bölümü olarak 1874 yılında Andrew Taylor Still tarafından oluşturulmuştur. A. Still’in bu yöntemi geliştirdiği dönem Amerika'da klasik tıp anlayışının yanı sıra, alopatik tıp anlayışı olarak yalnızca Çin tıbbının kabul gördüğü bir döneme denk geliyordu9 ${ }^{9}$. Kraniosakral terapi ve osteopati hastalıktan daha çok sağlık odaklıdır ve bütüncül tedavi yaklaşımını bizlere sunar. Vücudun kendi kendini iyileştirme mekanizmasından ve içsel dengeyi sağlamaya çalıştığından bahseder. Kranium bu dengeyi sağlamada en önemli parçadır. Kraniumdaki herhangi bir asimetri ya da patoloji mekanizmayı bütüncül olarak bozar9.

Kranium, insan vücudunun en üst pozisyonundaki beyin ve duyu organlarını taşıyan bölümü olarak adlandırılır. Kafatası toplamda (dil ve işitme hariç) 22 tane kemikten oluşur. Bu kemiklerden; Os frontale, Os parietale, Os occipitale, Os temporale, Os sphenoidale, Os ethmoidale neurocranium kemikleridir ${ }^{10}$. Neuro cranium oranının büyüklüğü beynin gelişmişliği ile doğru orantılırdır ${ }^{11}$. Bebek doğum kanalından geçerken frontal kemik düzleşir, oksipital kemik yerini değiştirir ve parietal kemikler biraz birbirinin üzerine biner. Doğumdan birkaç gün sonra bu durum normale döner ${ }^{12}$. Baş çevresi gelişimi önemli bir büyüme parametresidir. Yenidoğanda ortalama baş çevresi 34-35 cm olmalıdır. Kafatasındaki bu değişikliklerle beraber büyüme ve gelişmenin en hızlı olduğu periyot ilk iki yaştır. 15-16 yaşlarına kadar $\operatorname{artar}^{13}$. Kraniumdaki bu değişimler bizim hücrelerimizin canlılı̆̆ı, hayatı ve işlevi için önemli bir faaliyettir.

Temel felsefesi vücudun hastalık ve ya yapısal dengesizlikler nedeniyle bozulmuş olan kendi kendini iyileştirme mekanizmasını aktif hale etirmek olan Osteopati; pariatal, visseral ve kraniyal olarak üç bölümden meydana gelir ${ }^{14}$. Bu bağlamda kranial değerlendirme osteopati yöntemi içinde önemli yer tutar.

Antropometrik değerler arasında, kranium ölçümleri merkezi sinir sistemi ile en yakın olanıdır. Çocuklardaki bu asimetri ya da anomaliler belirlenen ölçümsel çalışmalarla daha da genişletilerek çalışmalar yapılmalıdır.

Büyüme ve gelişme normal gelişim basamaklarının iki ayrılmaz parçasıdır. Gelişme çoğunlukla fonksiyonel duruma ulaşma gelirken büyüme boy, yaş, kilo ve farklı organların kütlesel ve hacimsel artışı olarak tanımlanır ${ }^{13}$. Serebral Palsili bireylerde 
temel sorun çocuğun olması gereken normal gelişim basamaklarını takip edememesidir. Dolayısıyla bu duruma anormal ve yetersiz büyüme de eşlik eder. Özellikle kraniumdaki büyüme önemli bir parametredir 6,7,13.

Bizim bu çalışmada amacımız 1-12 yaş arasındaki Serebral Palsili bireylerde antropometrik ölçümler yardımıyla büyüme süreci, vücut antropometrisi, kranial büyüme hakkında veri toplamaktır. Çalışmamızdaki amacımız, bu çocuklarda olası kranial asimetrileri tespit ederek; kranial ortezler, ayak ortezleri ve ortodontik ürünler gibi birçok ürün ve tedavi için normatif veri toplamak ve bunların ortalama standartlarını ortaya koymaktır. Literatürde bu konuda yapılıııs çalışmanın az sayıda olduğunu ürün geliştiricilerin ve tedavi uygulayan uzmanların bu veriye ihtiyaç duyduğu kanısına vardık.

\section{Gereç ve Yöntem}

Bu çalışma bir fizik tedavi ve rehabilitasyon hastanesine gelen 1-12 yaş aralığındaki 24 Serebral Palsili ve aynı yaş grubundaki 22 sağlıklı birey üzerinde yapıldı (Tablo 1). Çalışmaya başlamadan önce Dr. Sadi Konuk Eğitim ve Araştırma Hastanesinden Tıbbi Etik Kurul izni alındı. Bu çalışma da 24 Serebral Palsi'li bireylerin 14'ü erkek 10’u kız, 22 sağlıklı bireyin 12'si erkek 10’u kızdı. Çocuklara değerlendirme yapılmadan önce ailelere çalışma hakkında bilgi verilmiştir. Daha sonra ailelere genel kurallar ve bilgilerin yazılı olduğu bir 'gönüllü bilgilendirme formu' imzalatılarak izin alınmıştır. Çalışmaya dahil etme ve dışlama kriterleri belirlenmiştir. Çalışmaya dâhil etme kriteri; 1-12 yaş arasında olmak, Serebral Palsi tanısı konulmuş olmak bulunmaktadır. Çalışmadan dışlama kriterleri; son altı ay içerisinde kafa çevresi ile ilgili bir cerrahi geçirmemiş olmak ve koma durumunda olmamaktır.

Tablo 1: Demografik ortalamalar

\begin{tabular}{|c|c|c|}
\hline & $\begin{array}{l}\text { Serebral Palsi Grubu } \\
(n=24)\end{array}$ & $\begin{array}{l}\text { Sağlıklı Çocuk Grubu } \\
(n=22)\end{array}$ \\
\hline Kilo (kg) & $\begin{array}{l}\text { Klz: } 13,6 \\
\text { Erkek: } 22,3\end{array}$ & $\begin{array}{l}\text { Kuz: } 30,09 \\
\text { Erkek: } 25,6\end{array}$ \\
\hline Вoy (cm) & $\begin{array}{l}\text { Kuz: 91,3 } \\
\text { Erkek 110,6 }\end{array}$ & $\begin{array}{l}\text { Kiz: } 131,1 \\
\text { Erkek: } 108\end{array}$ \\
\hline $\begin{array}{l}\text { Beden Kütle Índeksi } \\
\left(\mathrm{kg} / \mathrm{cm}^{2}\right)\end{array}$ & $\begin{array}{l}\text { Kuz: } 16,9 \\
\text { Erkek: } 17 \cdot 57\end{array}$ & $\begin{array}{l}\text { Kız: } 17,30 \\
\text { Erkek: } 18,09\end{array}$ \\
\hline
\end{tabular}


Bu çocuklarda baş çevresi ölçümü, kranial uzunluk, genişlik ve yükseklik ölçülmüştür. Baş çevresi ölçümü esnemeyen mezura yardımıyla yapıldı (Şekil 1,2). Kranial uzunluk, yükseklik, genişlik gibi değerler ise elektronik dijital kaliper ile ölçüldü5. Kranial kaliperin ölçüm birimi mm'dir. Ölçüm öncesi aile bilgilendirilmiştir. Ölçüm sırasında çocuk oturtulmuştur, oturma fonksiyonunu sağlayamayan çocuklar için bu pozisyon tekerlekli sandalyesinde desteklenerek sağlanmıştır. Ölçüm sırasında çocuğun öne ve arkaya gitmemesi sağlanmıştır. Ölçüm sırasında çocuğun desteklenmesi için velilerden yardım alınmıştır.

Şekil 1: Kranial kaliper ve esnemeyen mezura

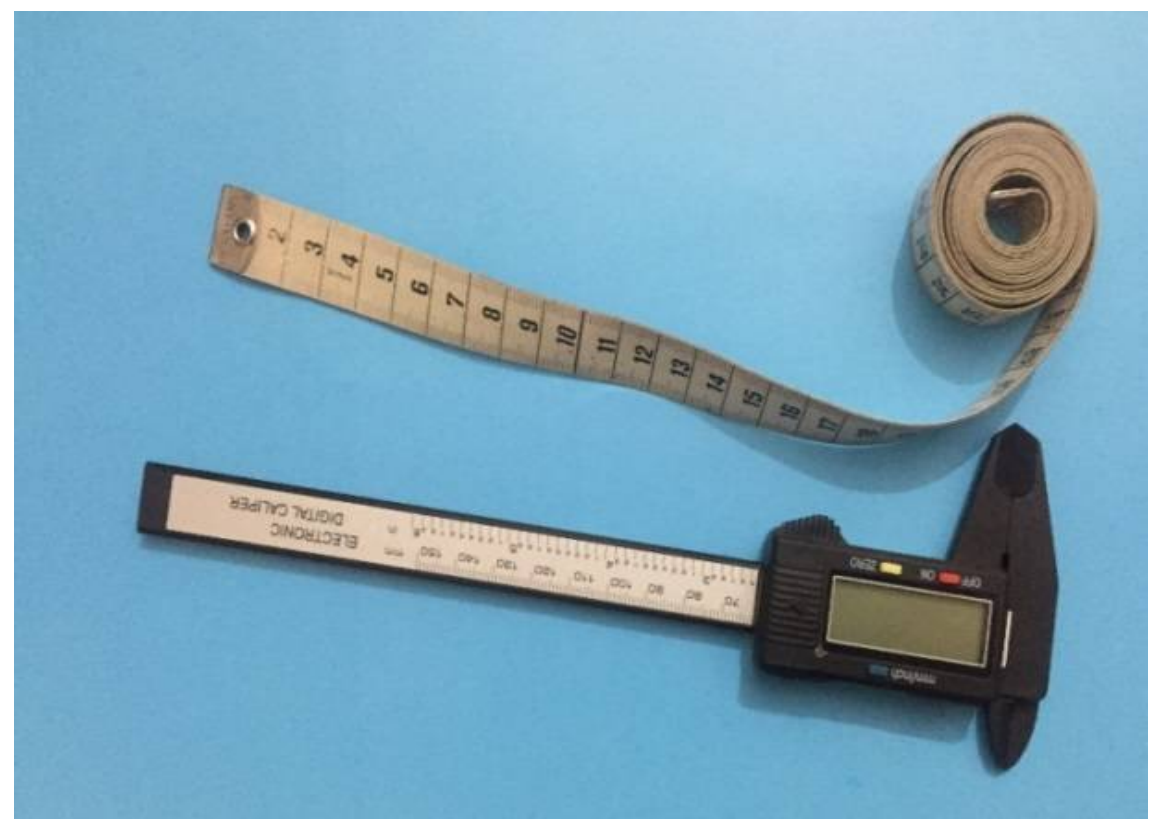

Demografik bilgileri kayıt için bir anket oluşturulmuştur. Oluşturulan bu anket ile ailede kalıtsal durumu etkileyen akraba evliliği sorgulanmıştır. Bireyin genel anamnezini almak için yaş, boy, kilo, doğum geçmişi, küvez geçmişi sorgulanmıştır. Konuşma ve görme yetisi, geçirilmiş cerrahi ve var olan Serebral Palsi tanısından başka bir tanısı olup olmadığı sisteme kayıt edilmiştir. 
Şekil 2: Kranial çapların kaliper ile ölçümü

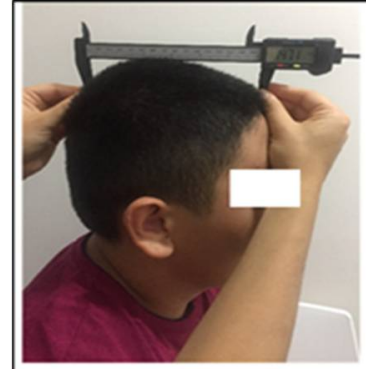

a) Uzunluk Ölçümü

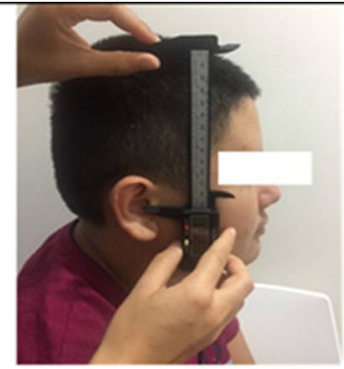

b) Yükseklik Ölçümü

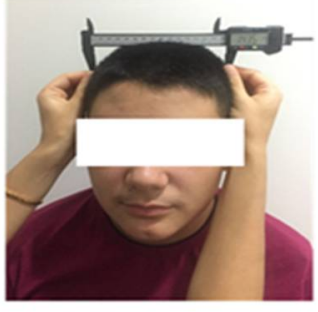

c) Genişlik Ölçümü

\section{Bulgular}

Bu çalışmaya 24 serebral palsili, 22 sağlıklı 46 birey alınmıştır. Serebral Palsili bireylerin kafa çapı ortalama (48 mm), uzunluğu $(136 \mathrm{~mm})$ ve genişliği $(123 \mathrm{~mm})$ ve sağlıklı bireylerin kafa çapı $(53 \mathrm{~mm})$, uzunluğu $(152 \mathrm{~mm})$ ve genişliği $(133 \mathrm{~m})$ idi. Serebral Palsili bireylerin değerleri, sağlıklı bireylerden anlamlı derecede düşüktü ( $\mathrm{p}=0.00, \mathrm{p}=0.00, \mathrm{p}=0.00)$. Ortalamalar arası farklar \%99 güven düzeyinde istatistiksel olarak anlamlıdır. Serebral Palsili bireylerin kranial çaplar sağlıklı bireylere göre düşüktür (Tablo 2).

Tablo 2: Sağlıklı ve serebral palsili bireylerin kranial çap ortamaları

\begin{tabular}{|l|l|l|l|}
\hline & $\begin{array}{l}\text { Serebral Palsi } \\
\text { Grubu (n=24) }\end{array}$ & $\begin{array}{l}\text { Sağlıklı Çocuk } \\
\text { Grubu (n=22) }\end{array}$ & Anlamlılık (p) \\
\hline Kafa Uzunluğu & $136 \mathrm{~mm}$ & $152 \mathrm{~mm}$ & $0.00^{*}$ \\
\hline Kafa Genişliği & $123 \mathrm{~mm}$ & $133 \mathrm{~mm}$ & $0.00^{*}$ \\
\hline Kafa Yüksekliği & $110 \mathrm{~mm}$ & $117 \mathrm{~mm}$ & $0.00^{*}$ \\
\hline Kafa Çapı & $48 \mathrm{~mm}$ & $53 \mathrm{~mm}$ & $0.00^{*}$ \\
\hline
\end{tabular}


Ölçüm yapılan çocukların demografik özellikleri istatistiksel olarak değerlendirilmiştir. Veriler SPSS 22,0 (IBM Turkey) programı ile değerlendirilmiştir. Serebral Palsili çocuklarda kranial asimetri sonuçları anlamlı bulunmuştur.

\section{Tartışma}

Antropometrik ölçümler fizyoterapistlerin kullandığı temel ölçme değerlendirme yöntemidir. Çalışmamıza göre serebral palsili bireylerde kranial çap sağlıklı bireylere göre daha düşük bulunmuştur.

Kelly ve ark. Çalışmalarda kafa uzunluk ve genişliği ölçümünü dikkate alırken, biz çalışmamızda kafa uzunluğu, genişliği ve yüksekliğine yer verdik. Kelly ve arkadaşları çalışmasında kranial düzleşmenin plagiosefalinin öncüsü olduğu kanısına varmışlardır ${ }^{16}$. Bizim çalışmamıza göre de serebral palsisli olgularda kafatası antropometrik değerleri, sağlıklı olgulara göre anlamlı derecede farklıdır. Van Vlimmeren ve ark. Plagiosefalinin sternokleoidomastoid kasının tek taraflı kontraktürü nedeni ile meydana geldiğini belirtmiş ve plagiosefaliyi dijital ölçümler ile belirlemiştir. Plagiosefaliye erken dönemde fizyoterapi uygulanması gerektiğini belirtmişlerdir ${ }^{17}$. Bizim çalışmamızda ölçüm için kranial kaliper kullanıldı ${ }^{15}$. Bizim çalışmamızda göre de serebral palsisli bireylerin kafatası antropometrik değerleri, sağlıklı çocuklarınkine göre anlamlı derecede farklıdır ve bu nedenle serebral palsili bireylerde erken fizyoterapide kranial mobilizasyon tedavisinin etkinliğinin araştırılması gerektiğini düşünüyoruz.

Bu çalışma sonucuna göre, kranial antropometrik değerlerin serebral palsili bireylerde daha geniş sayıda birey içeren çalışmalar dâhilinde yapılması gerektiği görüşündeyiz. Yenidoğanlarda araştırma yapan Stellwagen ve $\operatorname{ark}^{18}$. Yenidoğanların çoğunda yüz ve kafa asimetrisi olduğunu ve altı bireyden birinde tortikollis bulunduğunu bildirmişlerdir. Bizim çalışmamızda ise serebral palsili bireylerde kranial çap ölçümleri sağlıklı bireylere göre anlamlı derecede düşüktü. Literatür incelemesine göre kafatası asimetrileri ile tortikollis gibi bazı hastalıklar arasında bağlantı vardır, bizim çalışmamız ise Serebral Palsili bireyler ile sağlıklı bireylerin kafatası değerlerini karşılaştırmış ve istatistiksel olarak anlamlı farkllıklar olduğunu tespit etmiştir.

\section{Sonuç}

Araştırmamızın sonuçlarına göre serebral palsi hastalı̆̆ olan çocukların kranial 
antropometrik çapları sağlıklı çocuklara göre daha düşüktür. Bu durum bize kranial çap ve serebral palsi hastalığı hakkında bir ilişki olduğu bilgisini verdi. Araştırmamızın sonuçlarına göre kranial bölge antropometrik ölçümlerinin serebral palsi değerlendirmeleri içinde rutin olarak uygulanması ve kranial anormalliklerin fizyoterapistler tarafından göz önüne alınması gerektiği kanısına vardık.

Serebral palsi'li bieylerde kranial antropometri değerlendirmesinin önemli bir ölçme değerlendirne yöntemi olduğunu ve rutin olarak kullanılması gerektiğini düşünüyoruz. Serebral palsi konusunda uygulanan terapilerin ve fizyoterapistler tarafından uygulanan kranial mobilizasyonların da kranial çap değişimlerine nasıl etki ettiğinin sorgulanması konsunda ayrıca çalışmalara ihtiyaç vardır. Bu veriler osteopati gibi gelişen tamamlayıcı tıp yöntemleri ve manuel fizyoterapi uygulamaları için de veri oluşturacaktır.

\section{KAYNAKLAR}

1. Downs J, Blackmore AM, Epstein A, et al. The prevalence of mental health disorders and symptoms in children and adolescents with cerebral palsy: a systematic review and meta-analysis. Dev Med Child Neurol. 2018;60(1):30-38. doi: 10.1111/dmen.13555.

2. Yi TI, Jin JR, Kim SH, Han KH. Contributing factors analysis for the changes of the gross motor function in children with spastic cerebral palsy after physical therapy. Ann Rehabil Med. 2013;37(5):649-657.

3. Türkoğlu G, Türkoğlu S, Çelik C, et al. Intelligence, Functioning, and Related Factors in Children with Cerebral Palsy. Noro Psikiyatr Ars. 2017;4(1):33-37. doi: 10.5152/npa.2015.12676.

4. Ballester-Plané J, Laporta-Hoyos O, Macaya A, et al. Cognitive functioning in dyskinetic cerebral palsy: Its relation to motor function, communication and epilepsy. Eur J Paediatr Neurol. 2018;22(1):102-112. doi: 10.1016/j.ejpn.2017.10.006.

5. Gulati S, Sondhi V. Cerebral Palsy: An Overview. Indian J Pediatr. 2017. doi: 10.1007/s12098-017-2475-1.

6. Cloake T, Gardner A. The management of scoliosis in children with cerebral palsy: a review. J Spine Surg. 2016;2(4):299-309. 
7. Canadian Paediatric Society Statement Update. Positional plagiocephaly and sleep positioning: An update to the joint statement on sudden infant death syndrome. Paediatr Child Health. 2001; 6(10): 788-789.

8. Melunovic M, Haczagic-Catibusic F, Bilalovic V, et al. Anthropometric Parameters of Nutritional Status in Children with Cerebral Palsy. Mater Sociomed. 2017;29(1):68-72. doi: 10.5455/msm.2017.29.68-72.

9. Duymaz T. Mobilizasyon Teknikleri. Ankara: Hipokrat Yayınevi; 2017.

10. Liem T. Cranial Osteopathy: Principles and Practice. London: Churchill Livingstone; 2004.

11. Sargon MF. Kısa Anatomi. Ankara: Nobel Tıp Kitapevleri; 2012.

12. Sergueef N. Cranial Osteopathy for Infants, Children and Adolescents. London: Churchill Livingstone; 2007.

13. Gallahue D, Ozmun JC. Understanding Motor Development. 7th ed. New York: McGraw-Hill; 2012.

14. Yağcı N. Osteopathy approaches in Physiotherapy. J Physiother Rehbil-special Topics. 2015;1(2):35-42.

15. Skolnick GB, Naidoo SD, Nguyen DC, et al. Comparison of direct and digital measures of cranial vault asymmetry for assessment of plagiocephaly. $J$ Craniofac Surg. 2015;26(6):1900-1903. doi: 10.1097.

16. Kelly KM, Littlefield TR, Pomatto JK, et al. Importance of early recognition and treatment of deformational plagiocephaly with orthotic cranioplasty. Cleft Palate-Craniofac J. 1999;36:127-13016.

17. Van Vlimmeren LA, Van der Graaf Y, Boere-Boonekamp MM, et al. Effect of pediatric physical therapy on deformational plagiocephaly in children with positional preference: a randomized controlled trial. Arch Pediatr Adolesc Med. 2008;162(8):712-718. doi: 10.1001/archpedi.162.8.712.

18. Stellwagen L, Hubbard E, Chambers C. Torticollis. Facial asymmetry and plagiocephaly in normal newborns archives of disease in childhood. Arch Dis Child. 2008;93(10):827-831. doi: 10.1136/adc.2007.124123. 